\title{
O PROCESSO DE EMANCIPAÇÃO HUMANA NO ASSENTAMENTO ROSE: das ambiências do campo aos processos de constituição identitária
}

\author{
EL PROCESO DE EMANCIPACIÓN HUMANA EN EL ASENTAMIENTO ROSE: de \\ los ámbitos del campo a los procesos de constitución de la identidad
}

\author{
THE HUMAN EMANCIPATION PROCESS IN THE ROSE SETTLEMENT: from the \\ ambiences of the countryside to the processes of identity constitution
}

\author{
Leila Damiana Almeida dos Santos Souza ${ }^{1}$ \\ https://orcid.org/0000-0001-8491-2194 \\ Kleber Peixoto de Souza ${ }^{2}$ \\ https://orcid.org/0000-0003-4940-1465
}

\section{Resumo}

Ampliamos o foco, abrimos o olhar, aguçamos os ouvidos, ajustamos o compasso e carregamos nas cores. Foi assim que afinamos nossos passos para caminhar com um grupo moradores de um assentamento de reforma agrária, o Assentamento Rose, na cidade de Santaluz, BA. O objetivo foi evidenciar as formas de organização dos povos campesinos na luta pela emancipação individual e coletiva, bem como tornar conhecidas importantes questões sociais, políticas e epistemológicas que permeiam os saberes e os processos formativos dos homens e mulheres do Assentamento Rose. Optamos por uma investigação de natureza qualitativa. O estudo de caso foi a estratégia investigativa escolhida para conduzir as análises. Já a etnografia visual foi método que organizou e conduziu a investigação, abrindo possibilidades de uso variado de técnicas para construção dos dados, dentre elas as narrativas orais e outras técnicas como entrevistas e grupos focais. Concluímos que, a partir do movimento teórico-conceitual empreendido foi possível ampliarmos nossos olhares para a constituição identitária dos assentados do Rose, seja nos planos social, educativo, cultural e sócio-político. Ao identificarmos os saberes partilhados e o processo de emancipação humana que ali existem, não restam dúvidas que o contexto de luta, o preconceito e a criminalização cotidiana que sofreram esses campesinos, fizeram surgir uma dinâmica de

\footnotetext{
${ }^{1}$ Doutorando em Ciências da Educação, Mestre em Educação, Graduado em Pedagogia. Professor Adjunto da Universidade Federal do Recôncavo da Bahia (UFRB). Membro do Núcleo de Estudos, Pesquisas e Extensão em Tecnologia Assistiva e Acessibilidade (NETAA/CETENS/UFRB). E-mail: kleber.peixoto@ufrb.edu.br.

2 Doutora e Mestre em Cultura e Sociedade, Especialista em docência no ensino superior, Graduada em Pedagogia. Professora Adjunta da Universidade Federal do Recôncavo da Bahia (UFRB). Professora do Mestrado Profissional em Educação Científica, Inclusão e Diversidade da UFRB/Cetens. Vice-líder do Núcleo de Pesquisa sobre Formação para Docência e Ensino Superior (NUPEDES/CNPq).
}

E-mail: leila.damiana@ufrb.edu.br

Como referenciar este artigo:

SOUZA, L. D. S; SOUZA, K. P.. O processo de emancipação humana no Assentamento Rose: das ambiências do campo aos processos de constituição identitária. Revista Pedagógica, v. 23, p. 1-28, ano 2021.

DOI http://dx.doi.org/10.22196/rp.v22i0.6509 


\title{
Revista do Programa de Pós-Graduação em Educação da Unochapecó ISSN 1984-1566 (on-line) ISSN 1415-8175 (impressa)
}

produção e autoprodução através da qual esses povos se afirmam pelo saber produzido, bem como se afirmam como um coletivo culturalmente organizado e produtivo.

Palavras-chave: Camponeses. Cultura. Identidades. Saberes.

\section{Resumen}

Ampliamos el enfoque, abrimos los ojos, afinamos los oídos, ajustamos la marca de tiempo y cargamos los colores. Así afinamos nuestros pasos para caminar con un grupo de vecinos de un asentamiento de reforma agraria, el Asentamiento Rose, en la ciudad de Santaluz, BA. El objetivo fue resaltar las formas de organización de los pueblos campesinos en la lucha por la emancipación individual y colectiva, así como dar a conocer importantes cuestiones sociales, políticas y epistemológicas que permean los procesos de conocimiento y formación de hombres y mujeres en el Asentamiento Rosa. Optamos por una investigación de carácter cualitativo. El estudio de caso fue la estrategia de investigación elegida para realizar los análisis. La etnografía visual, por su parte, fue el método que organizó y condujo la investigación, abriendo posibilidades para el uso variado de técnicas de construcción de datos, incluyendo narrativas orales y otras técnicas como entrevistas y grupos focales. Concluimos que, a partir del movimiento teórico-conceptual emprendido, fue posible ampliar nuestras miradas hacia la constitución de la identidad de los colonos de el Rose, ya sea en los planos social, educativo, cultural y sociopolítico. Al identificar el conocimiento compartido y el proceso de emancipación humana que allí existe, no cabe duda de que el contexto de lucha, preconcepción y criminalización cotidiana que sufrieron estos campesinos, dio lugar a una dinámica de producción y autoproducción a través de la cual estas personas afirman por el conocimiento producido, así como afirmarse como un colectivo productivo y culturalmente organizado.

Palabras clave: Campesinos. Cultura. Identidades. Conocimiento.

\begin{abstract}
We widen the focus, we open our eyes, we sharpen our ears, we adjust the time signature and we load in the colors. That's how we tuned our steps to walk with a group of residents of an agrarian reform settlement, the Assentamento Rose, in the city of Santaluz, BA. The objective was to highlight the forms of organization of peasant peoples in the struggle for individual and collective emancipation, as well as to make known important social, political and epistemological issues that permeate the knowledge and training processes of men and women in the Rose Settlement. We opted for an investigation of a qualitative nature. The case study was the investigative strategy chosen to conduct the analyses. Visual ethnography, on the other hand, was the method that organized and conducted the investigation, opening up possibilities for the varied use of techniques for data construction, including oral narratives and other techniques such as interviews and focus groups. We conclude that, from the theoretical-conceptual movement undertaken, it was possible to broaden our views towards the constitution of identity of the Rose settlers, whether on the social, educational, cultural and socio-political levels. By identifying the shared knowledge and the process of human emancipation that exist there, there is no doubt that the context of struggle, prejudice and daily criminalization that these peasants suffered, gave rise to a dynamic of production and self-production through which these people assert themselves by the knowledge produced, as well as asserting themselves as a collective culturally organized and productive.
\end{abstract}

Keywords: Peasants. Culture. Identities. Knowledge. 


\section{INTRODUÇÃO}

A emancipação humana dos campesinos tem uma relação direta com as condições dignas para produzir e gerar renda através do cultivo da terra. O presente artigo traz resultados de uma investigação que objetivou evidenciar as formas de organização dos povos campesinos na luta pela emancipação individual e coletiva, bem como tornar conhecidas importantes questões sociais, políticas e epistemológicas que permeiam os saberes e os processos formativos dos homens e mulheres do Assentamento Rose.

Em consonância com as diretrizes do presente dossiê optamos por apresentar reflexões provenientes da investigação realizada com um grupo social que, certamente se inscreve nos grupos subalternos, e vem escrevendo cotidianamente as páginas da história através da organização político, social e produtiva dos agricultores do Assentamento Rose.

Não vamos pormenorizar as estratégias metodológicas utilizadas, pois, para os objetivos do presente dossiê, apresentarmos alguns debates e os resultados das nossas inserções no assentamento será suficiente para o que nos propomos. No entanto, demarcamos que a investigação foi de natureza qualitativa, sendo o estudo de caso a estratégia investigativa que conduziu as análises. Nos valemos da etnografia visual para conduzir a investigação, abrindo assim possibilidades para uso de variadas técnicas de construção dos dados, dentre elas as narrativas orais e entrevistas em grupos focais.

Nascer e viver numa região geográfica que sofre com as agruras climáticas, com o preconceito e com a falta de políticas públicas eficazes, deixam marcas no caminhar constitutivo dos povos que vivem nessa situação. Portanto, ao optarmos por estudar sobre os assentados do Rose, nosso posicionamento ético, político e epistemológico tem o objetivo contribuir para que se rompa com as estigmatizações do espaço rural, tão atacado e historicamente desprezado pelas políticas públicas no Brasil.

A problematização do presente estudo nos leva a um necessário retorno aos aspectos de constituição histórica do modelo agrário brasileiro e suas implicações para os povos do campo. Contudo, ressaltamos que não temos a pretensão de realizar um aprofundamento histórico acerca das implicações provenientes da organização social, política e econômica do nosso país. O que nos interessa, e o que nos permite a estrutura de um artigo, é demarcar que as opções pelo modelo agrário construído historicamente 
têm reflexos para os povos do campo, inclusive para os cidadãos do Assentamento Rose.

Sendo assim, na seção 1, apresentaremos alguns aspectos do lugar escolhido para realização do estudo. Em seguida, na seção 2, apresentamos uma breve incursão histórica sobre a questão agrária brasileira.

Não há como falar do lugar sem falar das vidas e das pessoas que o constitui. Falar das pessoas e do seu lugar sem adentrar nos modos de ser e agir desses povos seria negar a importância de fatos históricos que lançam luzes sobre aspectos que envolvem o espaço agrário brasileiro e de quem vive da terra e para terra.

\section{ASSENTAMENTO ROSE: UMA HISTÓRIA DE APRENDIZAGENS E ENSINAMENTOS}

O mesmo chão de onde brota a vida é o mesmo chão que chupa o sangue nos conflitos por terras. Foi num desses chãos que fomos ao encontro das histórias que constituíram o Assentamento Rose.

Foram as prosas com as lideranças da comunidade que nos permitiram conhecer os sonhos, as agruras e a mística do Assentamento. Fomos juntando várias vozes e nos valendo de estratégias diversas para compreendermos o sentimento de pertencimento dos moradores do Rose. Traçamos estratégias metodológicas que possibilitaram a relação de harmonia e confiança que, por sua vez, rendeu boas prosas nos almoços, merendas e passeios pelo Assentamento. Como fonte de pesquisa, utilizamos documentos disponibilizados por uma das lideranças, bem como a dissertação Mestrado de Edisvânio Nascimento (2018), que investigou as Narrativas Sisaleiras do Assentamento Rose.

A história do local tem início muito antes dos primeiros pés pisarem as terras do hoje conhecido Assentamento Rose. A busca de formação educacional na capital da Bahia, na década de 80, por alguns jovens que hoje são lideranças na região do Sisal; o contato com organizações como Comissão Pastoral da Terra (CPT); entidades como a Associação de Desenvolvimento Sustentável e Solidário da Região Sisaleira (APAEB), a Federação dos Trabalhadores Agricultores e Agricultoras Familiares (FETAG-BA) e outras, também foram fundamentais para configurar o contexto em que se deu a conquista da terra. No entanto, como veremos adiante, uma coisa foi o contato e as conversas iniciais, outra coisa foi a falta 
de apoio direto no momento da ocupação, bem como nos momentos de enfrentamento e organização político-social do acampamento e, posteriormente no assentamento.

O Projeto de Assentamento Federal (PA) é registrado no Instituto Nacional de Colonização e Reforma Agrária (INCRA) com o nome Lagoa do Boi. De acordo com o cadastro nacional do INCRA, está localizado no Município de Santaluz, numa área de aproximadamente 1.360 hectares. Conforme registro do órgão, a capacidade do PA é de 79 famílias. A data de criação oficial do Assentamento é 21/11/1995. Não estávamos interessados em dados oficiais, mas sim no processo histórico de organização e conquista da terra. Desejávamos conhecer a essência do local e de seu povo.

Os moradores remontam ao ano de 1988 para indicar que, à época, a empresa Estatal Companhia de Celulose da Bahia (CCB) era proprietárias da área em que hoje estão assentados. Segundo Sassáa (2019), essa mesma área foi entregue à empresa Klabin ${ }^{4}$ S.A. Entretanto, na ocasião da ocupação, a empresa já não atuava mais na Fazenda, embora fosse a proprietária. Como todas as demais, a luta para ocupação e assentamento nas terras da Lagoa do Boi teve suas particularidades.

Quando Valdir Pires foi Governador (1987 - 1989) eu fiquei sabendo dessa área aqui. Então procuramos a APAEB, mas eles disse assim: "A gente pode ajeitar umas lonas pra vocês ficar embaixo". Procurei um Vereador pra consegui um caminhão. Só o Sindicato de Santaluz que não apoiou a gente. Tivemos o apoio do Sindicato de Coité, a FETAG fez um compromisso e botou gente aqui. Como a gente tinha pessoa conhecida dentro do Governo de Valdir Pires nós fomos procurar. Então disseram: "Apoiar vocês a gente não apoia. Mas não vamos fazer nada. A polícia nem vai lá. A polícia só vai lá se vier ordem de Brasília”.

Aí veio a eleição de Lula e Collor. Só tinha de Lula nós aqui. Quando Collor ganhou o povo falava: "Agora vão é jogar uma bomba aí. Então um bocado foi embora". Tinha um Seminarista aqui, ligado a CPT, que uma liderança mandou pra ficar aqui com a gente, então decidimos: "Vamos falar com Collor." E se picamos! Chegamos lá fizemos um acampamento no Ministério da Agricultura, só eu e Ari (Seminarista). Daí veio o Ministro, todo empeletozado, era Antonio Cabrera, e disse: "Vamos subir". Quando chegou lá ele disse: "Eu tô a par disso já. É uma área da celulose, que era da Klabin. Nós já fizemos contato com o pessoal da Klabin. Fique tranquilos, pode avisar lá que não tem bomba, não tem nada. A gente vai tentar providenciar, Collor tem interesse em fazer a Reforma Agrária. Agora vamos avaliar, temos que negociar com os donos, porque não é do Estado, já é da Klabin. Mas a família parece que tem interesse".

Então saímos de lá e fomos atrás da Klabin. Chegamos lá o Dr. nós atendeu e disse: "A gente não tem interesse naquela área não. Nós temos interesse da fábrica lá em Camaçari. Aquilo ali entrou como contrapartida. A gente negociou e entrou aquela área na negociação, mas a gente não tem interesse não".

\footnotetext{
${ }^{3}$ Morador do assentamento e liderança na fase de ocupação do Assentamento.

${ }^{4}$ À época era denominada Klabin Fabricadora de Papel e Celulose - Unidade de Camaçari - BA.
} 


\section{Revista do Programa de Pós-Graduação em Educação da Unochapecó ISSN 1984-1566 (on-line) ISSN 1415-8175 (impressa)}

Então voltamos para a Bahia. Só que foi quando entrou Nilo Coelho (1989), latifundiário danado, então travou tudo. Então lá vai tudo de novo. Enchemos caminhão e ônibus de gente e fomos pra o Governo do Estado. Até que a Klabin entrou no meio e como eles deviam uns impostos pro Governo acabou liberando. Só que o título da terra é dado pela União, só o Governo Federal podia dar o título. Foi aquela confusão da saída do Collor, depois veio o topetinho (Itamar), veio Fernando Henrique. Então tivemos que ir pra Brasília de novo, foi eu e Ezequiel. Explicamos que tava tudo certo que só era assinar. Então fomos ao INCRA e preparamos toda a papelada. Depois de quatro meses o INCRA resolveu tudo. (Informação Verbal, SASSÁ, 2019).

Como veremos na discussão sobre a questão agrária - seção 2-, no Brasil, os grupos com maior poder econômico, recorrentemente reivindicam a propriedade de terras, mesmo que delas não sejam os verdadeiros donos. Na Fazenda Lagoa do Boi, não foi diferente. Como a Klabin não produzia na área, criadores da região ocupavam a fazenda, sentindo-se os "donos" daquelas terras abandonadas, (EZEQUIEL apud NASCIMENTO, 2018, p.). Se os fazendeiros, que já tinham suas terras agiam como proprietários de algo que não lhes pertencia, porque os trabalhadores rurais não podiam reivindicar essa mesma área? Mas, só o desejo não bastava, era preciso organização.

Toda essa luta foi construída a partir de desejos individuais, contudo, houve a tentativa de conseguir o suporte - não só apoio verbal - de parceiros ligados aos movimentos sociais. Um dos líderes da época da ocupação fala sobre os parceiros.

\footnotetext{
Contamos com apoio dos sindicatos de Coité, Riachão, Retiro e Valente. Quando cheguei aqui fui atrás de um pessoal da Associação do Açude Tapera e pedi para me arrumar um pessoal de Santaluz porque só iria vir gente de fora. Já tinha 50 famílias de fora, mas tinha que ter de Santaluz, como é que reivindicava uma área da cidade e não tinha ninguém de lá? No dia da ocupação quando chegamos aqui já tinha 70 famílias de Santaluz, mas nem o presidente do sindicato tava aqui, porque correu. O pessoal da Associação do Açude Tapera também nem apareceu. A gente pegou o carro e fomos. Ocupamos a área e depois de uns quinze dias o povo começou a ficar agoniado. Quando a polícia veio a primeira vez, correu logo um bocado e não voltou mais. Primeiro foguete que teve correu todo mundo (risos). Ficou umas 10 famílias e outros ficaram só como trabalhador. (Informação Verbal, SASSÁ, 2019).
}

As condições são as mais adversas possíveis para as pessoas simples do campo que optam em deixar o julgo do patrão e lutar pela terra. Acreditamos que, para muitos, a busca por sobrevivência é que impulsiona a luta pela terra: "eu mesmo não tinha terra pra morar, fazer uma casa... pra criar... tipo um criatório, não tinha. Trabalhava pro fazendeiro e 


\section{Revista do Programa de Pós-Graduação em Educação da Unochapecó ISSN 1984-1566 (on-line) ISSN 1415-8175 (impressa)}

morava justamente na terra do fazendeiro" (LOLÔ, 2018)5 . Mesmo em condições precárias, vivendo anos em barracas de lona, a crença em dias melhores faz brotar uma inexplicável força: "na ocasião tínhamos 120 barracas, aproximadamente 400 pessoas e passamos quatro anos nessa situação" (EZEQUIEL, 2013)

Chegando a terra, foi preciso enfrentar muito mais que as intempéries da natureza e as condições adversas. Foi preciso uma organização capaz de fortalecer o coletivo dos ataques de fazendeiros e do poder público, ações que buscassem a horizontalidade das decisões e definição de regras para garantir a unidade na caminhada. Com esse propósito de organizar e fortalecer o grupo, criam nos primeiros dias de ocupação o Grupo dos 33. Evidencia-se, mais uma vez que, os movimentos sociais que foram contatados para apoiar desde o início da ocupação não se fizeram efetivamente presentes. Portanto, a organização política, social e produtiva do Rose foi bastante peculiar.

Nessa caminhada, as mulheres e homens que ainda viviam em barracas de lonas sentiram a necessidade de instituir um grupo que primasse pela organização coletiva, discutisse coletivamente as demandas e tirasse encaminhamentos balizados pelos princípios da justiça e da igualdade. Foi então que surgiu o Grupo dos 33: "foram chamados para compor esse grupo mulheres e homens que faziam parte do acampamento. Dentre os objetivos estava a igualdade na distribuição e partilha das rendas adquiridas pelos acampados nos trabalhos coletivos na terra" (SOL, 2019). A gênese e algumas ações do Grupo dos 33 são apresentadas com detalhes pelo líder Sassá (2019).

Quando a gente chegou era muito complicado para eu sozinho dá conta, era gente de oito municípios. Eu já tinha saindo nas comunidades, mas a gente não sabia com quem a gente tava lutando. Ficava muito pesado pra eu decidir as coisas mais pesadas. Então lancei a ideia da gente lançar um grupo pra formar a constituinte do local, que seria as leis que iria reger a partir daquele dia. Em 12 de julho de 1989, nós criamos um grupo chamado os 33, a idade de Cristo. Então juntou mulher, homem, todo mundo que queria participar. Com oito dias já tivemos um problema sério. Dois caras foram pra rua se embebedaram e mandei pros 33. Aí lá um falou; o outro fez a defesa também. Então decidiu que um dos que tava errado tinha que ir embora. Botamos tudo que ele trouxe no carro e ele foi embora. Tinha três punições: Lei mínima, que era uma advertência; Lei média que era uma pena, que teria que fazer uma roçagem pra comunidade, a gente tinha roça comunitária; e a Lei máxima que era expulsão mesmo. Os meninos tinha um medo danado, quando eles aprontavam

\footnotetext{
${ }^{5}$ Fala do Sr. Lolô, concedida ao pesquisador Edsvânio Nascimento, 2018. É um assentado de 58 anos, foi um dos que primeiros chegaram a terra.

6 Depoimento no Programa Globo Rural. 04 de agosto de 2013. https://www.youtube.com/watch?v=OzLoxcVnell
} 
alguém dizia: "Olha que vou mandar para os 33". Os 33 ficou até dezembro de 1990, quando criamos a Associação. Os critérios se manteve, porém, os 33 foi extinto. (Informação Verbal, SASSÁ, 2019).

Dentre as decisões desse período, uma tem grande simbologia: a definição do nome do Assentamento. Grande consternação tomou conta dos movimentos sociais do campo em março de 1987. Roseli Celeste Nunes da Silva, a Rose, era uma mulher que se destacava entre os mais de 7 mil agricultores que ocupavam, desde 1985, a Fazenda Annoni, latifúndio improdutivo de mais de 9 mil hectares localizado no Rio Grande do Sul, no município de Pontão. Rose, estava nas fileiras de camponeses que marcharam mais de $300 \mathrm{~km}$ até Porto Alegre, para ocuparam a Assembleia Legislativa, onde permaneceram por dois meses, até conseguirem solução para os acampados da Fazenda Annoni. Durante um protesto na BR386, em Sarandi, no dia 31 de março de 1987, um caminhão avançou contra uma barreira humana e vitimou 17 agricultores, sendo que três morreram, dentre eles, Rose.

Ainda no período em que o Grupo dos 33 coordenava a ocupação e os moradores ainda residiam em barracas de lona, nasceu a primeira criança. Então tomaram duas decisões: primeiro a criança se chamaria Rose Terra de Oliveira Mota, uma homenagem a líder morta no Rio Grande do Sul e à terra; a segunda decisão foi que a localidade passaria a se chamar Comunidade Rose (Povoado Rose). Então, no contexto da organização, o nome da pessoa e do lugar surgem repletos de implicações política, afetiva e social. Ainda hoje, se ouve pessoas usarem nomes diferentes para se referir ao lugar, pois o Projeto de Assentamento é Lagoa do Boi e a comunidade é a calorosa Rose.

A associação acima referida é a Associação dos Pequenos Agricultores da Comunidade Rose (APACOR). Com a APACOR, a organização do assentamento ganha uma institucionalização que permitiu, além da estruturação interna, saírem em busca de políticas públicas e financiamentos para as atividades produtivas, culturais, educativas e desportivas da comunidade. Dentre os muitos ensinamentos das lutas, que se iniciam com uma ocupação e seguem quando se assentam na terra, estão a capacidade de resistir e reexistir. A chamada organicidade do movimento, como diz Peloso (2012), reflete a capacidade das lideranças em articular as ideias e orientações, de modo a garantir a unidade de pensamento e de ação. Luta, resistência, labor, educação, cultura, sabores e saberes; tudo faz parte de uma unidade.

Ademar Bogo (2010), ao tratar da capacidade de organização das lideranças nos diz 


\section{Revista do Programa de Pós-Graduação em Educação da Unochapecó ISSN 1984-1566 (on-line) ISSN 1415-8175 (impressa)}

que: “Autonomia significa não depender de ninguém para fazer o que queremos. Os movimentos do campo precisam saber que em si está a solução do campo, e é por seu próprio esforço que virá a emancipação" (BOGO, 2010, p. 175). Evidenciamos que o objetivo do presente estudo não é aprofundar a dinâmica do movimento, mas, sinalizar que essa organicidade, consequentemente a busca da citada autonomia, se faz necessária quando na luta pela terra está presente a opção pela resistência e pela re-existência.

As dimensões, democrática e participativa, se fazem presentes no Assentamento Rose. Por lá, os espaços estão à disposição de todos. Os processos educativos ${ }^{7}$ perpassam todos os locais e todas as gerações. A cultura se espalha por todos os cantos: são os griôs sisaleiros; são os cantadores e contadoras de causos; são as sambadeiras do grupo Rosas Vivas; é o Projeto Expressões Sertanejas; são as oficinas de artes.

O processo de ocupação de uma terra improdutiva, tendo como protagonistas pessoas simples - a quem sempre foram negados diversos direitos básicos, tem muito a ensinar. As bases educativas, culturais e políticas de uma ocupação como a do Rose podem revelar uma forma de lutar capaz de ensinar, inclusive aos movimentos sociais.

A dimensão cultural é uma dessas formas de resistência no Rose. Inicialmente, olhamos para fora do assentamento com o intuito de alcançar as tentativas de sucumbir aos processos culturais e educativos que ali nasceram. Não é segredo que, na sociedade brasileira, setores conservadores promovem discursos que acabam atribuindo aos povos do campo uma identidade relacionada ao atraso e, quando não, à violência. Se esses campesinos forem de assentamentos, então essas identidades atribuídas serão ainda mais sustentadas em práticas estigmatizadoras e discriminatórias. Esse modo de definir o outro pelo preconceito é feito indistintamente, pois num assentamento, crianças, jovens, adultos e idosos são colocados no mesmo patamar de criminalização. Portanto, fica evidente que posições como essas também se sustentam na negação cultural desses povos.

Se existe essa atribuição identitária por um lado, por outro estão as resistências contra - hegemônicas que constroem as possibilidades de reafirmação individual e coletiva desses povos. O Rose é uma prova viva dessas possibilidades. Então, faz-se necessário olhar para dentro do Assentamento, com objetivo de romper as cercas e demonstrar para

\footnotetext{
${ }^{7}$ Infelizmente, devido a limitação de páginas do artigo, as discussões sobre as perspectivas educacional e cultural não serão aprofundadas nessa publicação. Contudo, falaremos delas em linhas gerais.
} 
os desavisados a perspectiva de cultura, memória e identidade que perpassam as vidas de crianças e adultos assentados numa área de reforma agrária.

Os homens e as mulheres que em 1989 chegaram numa terra desconhecida já teciam suas teias de significados. Cada um trazia suas vivências culturais e agora estavam reunidos com pessoas de diferentes lugares com objetivos comuns; ocupar, resistir e produzir $^{8}$. Para resistir às condições adversas, era preciso produzir uma nova forma de existência, foi então que a cultura - nas suas formas mais singelas - começou a ser uma ação intencional no cotidiano dos acampados. Relembrando os primeiros momentos, a professora Sol (2019) recorda algumas ações de resistência: "a gente passou por tudo isso, mas nós tínhamos as cantigas de roda, o show de calouros de Zicks mais Miguel. Assim, por mais que tivessem esses sofrimentos, nós seguimos" (Informação Verbal, SOL, 2019).

A importância da cultura como resistência é reforçada pela voz de quem passava o dia na lida com a terra, mas à noite via nas atividades culturais uma forma de manter a união e seguir firme na ocupação:

\begin{abstract}
Como algo de alegria, porque a gente, no caso, não cheguemos a abaixar, no caso, como diz assim, abaixar o pescoço pra fazendeiro montar. Sempre a gente fazia, toda semana a gente fazia assim, uma brincadeira de show de calouro. Ezequiel era quem mais fazia a frente, e aí a gente sempre andava alegre, a gente não andava, dizendo assim "nós tamos triste e vai se entregar aos fazendeiro; fazendeiro vai tomar conta da gente, vai expulsar a gente daqui de dentro". Não, a gente sempre tinha aquele algo de alegria que a gente não andava triste, a gente sempre ia... botava pra frente pra poder Deus abençoar que dava tudo certo. (Informação Verbal, LOLÔ, 2017) ${ }^{9}$.
\end{abstract}

Duas pessoas e a mesma significação para o momento que servia como chama da resistência. Outras vozes que ouvimos demonstraram a mesma percepção: os momentos em que partilhavam seus saberes e alegrias serviram para fortalecer a coletividade e demonstrar que não bastava disposição para lutar, mas a união e a alegria seriam fundamentais para não aceitarem o jugo imposto pelos fazendeiros e ainda suavizar o fardo da lida na roça.

A força da cultura sempre foi percebida no Rose. O cultural, o educacional, o social, o político, o individual e o familiar; tudo se interpenetrando e desenhando um modo de

\footnotetext{
${ }^{8}$ Esse é um lema do MST, contudo, cremos que esses objetivos também se fizeram presentes na ocupação do Assentamento Rose.

${ }^{9}$ LOLÔ. Entrevista concedida para NASCIMENTO, 2018.
} 


\section{Revista do Programa de Pós-Graduação em Educação da Unochapecó ISSN 1984-1566 (on-line) ISSN 1415-8175 (impressa)}

vida muito próprio do assentamento. Isso foi possível devido à percepção de que aqueles momentos em que se reuniam para as cantorias e causos não eram apenas uma "folclorização" das tradições. Como diz uma das lideranças: "através da música, do samba de roda, da moda de viola e de várias outras manifestações artístico-culturais a gente conseguiu unir a comunidade e fazer com que ela se desenvolvesse no campo econômico, educacional”. (Informação Verbal, ROQUINHO, 2017).

Com essa imbricação entre o cultural, o político, o educacional e o econômico os projetos foram surgindo. Ainda hoje existe no assentamento: os (as) Griôs Sisaleiros (as) e o grupo Rosas Vivas, ambos com nível de abrangência local - mas com alcance regional e nacional, o primeiro formado por homens e mulheres que tem como objetivo o reconhecimento, valorização e divulgação das diversas práticas artístico-culturais que perpassam a historicidade da comunidade. Já o grupo Rosas Vivas é considerado como uma expressão de gênero. Surgiu interligado com os Griôs Sisaleiros, contudo mantém uma linha de atuação conduzida pelas mulheres. As mulheres são as compositoras de cantigas que retratam o cotidiano da cidade e do campo, bem como desenvolvem as rodas de samba onde as composições são difundidas para todos os assentados e para outros que tem o prazer de participar dos ricos momentos culturais. Inclusive para aqueles que tem o prazer de conhecer o trabalho através do CD gravado pelo grupo.

Outras importantes ações, desenvolvidas no âmbito municipal e regional, acontecem em torno da Liga Desportiva e Cultural dos Assentamentos da Região Sisaleira (LIDER). Essa foi a forma pensada para criar uma articulação regional dos assentamentos, visto que o Rose não está dentro do modelo de organização camponesa de nível nacional. Essa articulação permite o fortalecimento de ações em diferentes frentes.

A preocupação que as questões de gênero vão além da perspectiva cultural. A partir dos questionamentos que as mulheres faziam do seu papel no assentamento, em 2004 nasce o Grupo de Mulheres Produtoras da Comunidade de Rose (GMPR). Um grupo coordenado apenas por mulheres, onde as decisões são tomadas de forma colegiada por um grupo de 20 delas. Foi a partir do GMPR que as mulheres - agricultoras familiares - se uniram para produzir sequilhos, broas, beijus e bolos. Também decidiram cuidar e comercializar hortaliças cultivadas em hortas próprias.

No processo de emancipação que acontece no Rose, as dimensões cultural, política 


\section{Revista do Programa de Pós-Graduação em Educação da Unochapecó} ISSN 1984-1566 (on-line) ISSN 1415-8175 (impressa)

e econômica estão diretamente relacionadas às aprendizagens e vivências democráticas, que se iniciam ainda na infância. Os projetos escolares permitem às crianças alçarem voos, inclusive levando algumas delas Além-Mar, quando foram representar o Brasil em Portugal nas comemorações dos 500 anos do descobrimento.

A ideia da caminhada que não se faz só é uma marca da comunidade, desde os tempos da ocupação. Além da organização em torno do Grupo do 33, que depois se tornou a Associação dos Pequenos Agricultores da Comunidade Rose (APACOR), evidenciamos que nas estratégias de enfrentamento a participação democrática das crianças e pensada de forma objetiva no Rose. Ou seja, se existem experiências singulares realizadas pelas mulheres, o mesmo acontece com as crianças e adolescentes; trata-se de iniciativas como a rádio poste, a Prefeitura e Câmara de Vereadores Mirins.

A rádio poste não é só um espaço de informação e divulgação das atividades do Rose, também tem caráter formativo. Através de uma estrutura de rádio difusora, montada para ecoar informações e músicas nos alto falantes dos postes, os jovens são convidados para se tornarem os radialistas. Os resultados são: um poder de comunicação e jovens que viraram locutores de rádios oficiais com alcance em toda região sisaleira.

Nas andanças pelo assentamento, quando éramos apresentados alguém ouvíamos a seguinte referência: “Esse foi já Prefeito Mirim”. "Essa foi a primeira mulher eleita Prefeita Mirim. “Esse foi o Vereador Mirim mais votado de toda história do Rose”. Aquelas falas aguçaram nossa curiosidade, foi então que ouvirmos: "Essas crianças que passam pela experiência da prefeitura mirim se destacam em todas as atividades que se envolvem fora daqui (Informação Verbal, SASSÁ, 2019). Percebemos que estávamos diante de uma situação clara que envolvia os processos identitários.

Essa iniciativa surgiu no ano de 2007, com a intenção de que crianças e jovens vivenciassem experiências de participação democrática dentro do Assentamento. A dimensão que tomou não tinha sido imaginada nos melhores cenários. Trata-se de um processo em que chapas com candidatos (as) a Prefeito (a) e Vice são inscritas. Da mesma forma, as candidaturas individuais para Vereador (a). As chapas majoritárias apresentam sua plataforma de governo e participam de debates na comunidade. Para Vereador (a) são disponibilizadas 07 vagas e o mais votado (a) torna-se o (a) Presidente da Câmara. Os eleitores são todos os moradores do Assentamento, principalmente as crianças e os 


\title{
Revista do Programa de Pós-Graduação em Educação da Unochapecó ISSN 1984-1566 (on-line) ISSN 1415-8175 (impressa)
}

jovens. Eleitas, essas crianças e jovens vão participar com suas proposições das plenárias da Associação levando suas pautas e participando da execução de ações.

O que não imaginavam os adultos era que o Assentamento Rose seria pequeno para o significado dessa ação. Outros assentamentos passaram a eleger também seus (suas) Prefeitos (as) e Vereadores (as) Mirins. As crianças também passaram a fazer gestões diretamente na Prefeitura e na Câmara de Vereadores do município de Santaluz, tendo, inclusive, sessão de posse dos mandatos na casa legislativa municipal.

Para aqueles que viveram essas experiências as marcas são evidentes. Levinho, nascido no Rose, é filho de um casal de assentados que participaram de toda a elaboração prévia da ocupação e estiveram à frente das primeiras ações, desde a fase de acampamento. Estudou na escola da comunidade e se formou Técnico em Agropecuária, hoje é concursado da Secretaria de Agricultura do Município de Araci/BA, também é licenciado em Filosofia pela Universidade Estadual de Feira de Santana (UEFS).

\begin{abstract}
Falar sobre a Prefeitura Mirim me traz boas recordações. De fato, teve muita importância na minha vida e na minha trajetória. No caso eu fui eleito como Vereador Mirim na primeira eleição. Fui eleito para ser o Presidente da Câmara dos Vereadores, porque fui o Vereador que teve mais votos na comunidade. Eu achei importante este trabalho desenvolvido na Prefeitura Mirim porque empodera a criança desde cedo para se envolver nas questões políticas, em pensar como melhorar sua comunidade, como agir com as pessoas, como ser um ser social envolvido politicamente. (Informação Verbal, LEVINHO, 2019).
\end{abstract}

Ali, misturado com suor, lágrimas, memórias e sorrisos estavam os processos culturais e identitários, bem como as Culturas da Infância que dão singularidade às crianças e adultos campesinos. As culturas ali estavam porque, como diz Corsaro (2011, p. 37), essas culturas das crianças são "um conjunto estável de atividades ou rotinas, artefactos, valores e ideias que as crianças produzem e partilham em interacção com os seus pares”. Também ali estava a memória, sendo esta, à luz dos estudos de Michael Pollak (1992, p. 204) considerada "um fenômeno construído social e individualmente". Sendo que o autor ainda amplia a relação da memória com os processos identitários ao dizer que:

[...] a memória é um elemento constituinte do sentimento de identidade, tanto individual como coletiva, na medida em que ela é também um fator extremamente importante do sentimento de continuidade e de coerência de uma pessoa ou de um grupo em sua reconstrução de si. (POLLAK, 1992, p. 204). 
Ali estão presentes uma profusão de saberes, as estratégias do movimento social para superação de excelência e os processos educativos, culturais e dialógicos que corroboram para a emancipação de todos os assentados.

\section{A QUESTÃO AGRÁRIA: o campesino se constitui nas excludências}

Temos claro que, optar por uma linha argumentativa acerca do processo histórico da formação da economia agrária brasileira é caminhar por um terreno laborioso, pois estão longe de serem consensuais as abordagens que tratam da constituição da questão agrária brasileira e suas características atuais. Para João Pedro Stedeli (2011) existem diferentes concepções política-epistemológicas, a partir das quais se opta para analisar o conceito de questão agrária. As diversas formas de se trabalhar e interpretar esse conceito dependerá da ênfase que se quer dar aos aspectos do estudo acerca da realidade agrária.

Optamos, mesmo que brevemente, por uma discussão da questão agrária envolta em um conjunto de interpretações históricas da realidade agrária, que buscam explicar como se organizou a posse, a propriedade e o uso das terras na sociedade brasileira, sobretudo como os campesinos se organizaram na contradição dos processos de exclusão.

A terra sempre tem um dono e esse espaço delimitado tem um valor econômico. No Assentamento Rose, nos deparamos com um olhar para a terra que vai além dessa dimensão da terra-capital. Numa das conversas, a professora da comunidade nos disse: "a terra só pode ser passada para alguém que vive no assentamento e que é da família. Se for assim, calcula o trabalho desenvolvido na terra e pode passar o trabalho para outro" (Informação Verbal, SOL, 2019 - Entrevista).

Eis uma extraordinária diferença nas relações sociais perpassadas pela terra. No Rose, o foco não está na propriedade privada e nas relações comerciais, mas na dimensão humana, capaz de transformar o solo árido em renda para a sobrevivência. Os princípios da coletividade que envolve o trabalho, a produção e a divisão da renda é um dos diferenciais do Rose.

Devido essa forma diferenciada de tratar a terra e o que ela oferece que, mesmo após termos apresentado alguns elementos do Assentamento, consideramos importante 
adentrar em alguns aspectos da questão agrária brasileira.

Desde a ocupação e colonização do território brasileiro, o monopólio da terra se institucionalizou. Moisés Vinhas (2011) diz que: “o acentuado grau de concentração da propriedade fundiária que caracteriza a estrutura agrária brasileira é reflexo da natureza de nossa economia e resulta da formação do país desde os primórdios da colonização" (VINHAS, 2011, p. 137). Sim, a estrutura agrária do Brasil foi profundamente marcada pelas relações econômicas e comerciais do período colonial. É evidente que as relações econômicas, políticas e sociais do período colonial brasileiro foram profundamente influenciadas pelas relações mercantilistas europeias da época.

Diante dos diversos campos teóricos que analisam a questão agrária na colônia, optamos pelas construções de uma corrente que apresenta certa hegemonia na interpretação da evolução da questão agrária. Essa corrente defende que nesse período histórico, para os detentores do poder na Europa, tudo deveria ser transformado em mercadoria.

À época do descobrimento, não só Portugal, mas também grande parte dos países da Europa encontrava-se em pleno desenvolvimento do mercantilismo. Segundo Guimarães (1997), “o regime feudal desagregava-se, o poder absoluto da aristocracia agrária entrava em decomposição e os senhores de terras que escapavam à ruína, buscavam, nas atividades urbanas, novos caminhos para a conservação de seus privilégios" (GUIMARÃES, 1997 apud STEDELI, 2011, p. 35).

Sendo a terra o mais importante dos meios de produção, uma coisa era certa, os recursos para a empreitada colonizadora não poderiam sair do erário real. Foram então concedidas grandes concessões aos fidalgos e nobres, sendo alguns deles ricos proprietários e outros já experimentados nas expedições das Índias.

Várias são as peculiaridades do modelo de ocupação da terra no Brasil. Uma delas é que em outras partes do mundo houve a transformação do escravo em servo da gleba, mudando assim as características do feudalismo clássico. Como não foi possível contar com o servo da gleba e houve dificuldades na domesticação plena dos nativos, por aqui os proprietários das terras se valeram da mão de obra escrava já extinta na Europa. Se por um lado o aumento da produtividade percebido em Portugal com os servos da gleba não aconteceu no Brasil, por outro, houve uma compensação devido à alta fertilidade das 
terras brasileiras. Também se buscou garantir a produtividade aplicando um rígido e desumano controle da mão de obra.

Diversas páginas necessitariam serem escritas para discutir o trabalho escravo, os ganhos que os poderosos tiveram com o tráfico negreiro. Outras tantas páginas caberiam na tentativa de apresentar as "perdas" que esses mesmos poderosos tiveram com a abolição da escravatura e, sobretudo, a condição de abandono que ficou o negro alforriado. Entretanto, relembro que nossa opção é demarcar as formas históricas de ocupação da terra e suas implicações na má distribuição das terras.

Historicamente, observa-se que o latifúndio se refaz de forma cruel. Essa reestruturação pode ser percebida pela manutenção do monopólio da terra e, sobretudo, pelas novas formas servis de trabalho que substituíram os braços escravizados. O latifúndio encontrou formas de prolongar a cruel exploração semi-escravista ou semi servil. Foi nessas tentativas de manter o domínio por meio da terra que a Coroa Portuguesa adaptou para a realidade brasileira o regime das sesmarias. Como necessitaríamos de várias páginas para descortinar esse sistema que viabilizou a apropriação de terras no Brasil, nos limitaremos a dizer que a chamada sesmaria estava longe de ser apenas a distribuição de lotes de terras com o objetivo de cultivar no novo mundo, pois, tudo que envolveu a instituição das sesmarias, e os impactos delas advindos, tem sua gênese na entrega de generosas porções de terras e a consequente criação dos latifúndios. As desigualdades que daí surgiram, e vigoram ainda hoje no país, são muito maiores que os fatos que superficialmente descrevem os livros didáticos.

Diante da crise que passava Portugal, a fidalguia foi incentivada a desembarcar no Brasil, pois eram garantidas grandes extensões de terras e, tão importante quanto, passariam a cultivar um produto milagroso, o açúcar. O ouro branco foi capaz de modificar os rumos da história. O açúcar teve uma função na ocupação da terra, pois possibilitou que Portugal encontrasse a solução para um dos seus problemas da época, a comercialização. Amparados na certeza de grandes lucros, atraiu a classe dos mercadores que tinham como prepostos na empresa do açúcar influentes intermediários e nobres banqueiros.

O modo de produção implantado a partir do cultivo do açúcar influenciou a organização de toda a sociedade que se estruturava. Certamente, foi um modo sui generis de produção, agregando elementos de dois regimes econômicos: o regime feudal da 


\section{Revista do Programa de Pós-Graduação em Educação da Unochapecó ISSN 1984-1566 (on-line) ISSN 1415-8175 (impressa)}

propriedade e o regime escravista do trabalho. As bases da política econômica da colônia se apoiavam em dois regimentos: a sesmaria e o engenho. O primeiro se transformou numa unidade econômica e o segundo numa unidade produtora.

Mas essa lógica só perduraria se o trabalho escravo fosse mantido; se as terras não ficassem devolutas e não se intensificasse a estratificação das sesmarias. Entretanto, existiram não só os problemas surgidos com a estratificação da propriedade sesmeira, mas, também foi percebido o desenfreado ciclo de mineração que produziu consequências desastrosas para a lavoura brasileira. Os campos ficaram abandonados e as atividades agrícolas declinaram, mas uma minoria de poderosos resistia às dificuldades, adquiria mais terras e enriqueciam ainda mais. Com a baixa nas atividades mineradoras, o que se via de um lado eram um monopólio das terras nas mãos de poucos e, por outro lado, havia terras abandonadas e uma enorme massa humana privada de trabalho que marchava para os centros urbanos com precárias estruturas.

Diante da crise a Coroa se viu obrigada a extinguir o regime das sesmarias, mas, imediatamente reestruturou a forma de ocupação da terra. Ou seja, lançaram mão de novas estratégias para manter o monopólio da terra nas mãos dos poderosos. Para restringir os direitos sobre as terras doadas, cria-se o primeiro dispositivo para regularizar a situação fundiária no Brasil, a Lei de Terras (1850). Ficava estabelecido a compra como a única forma de acesso à terra e abolia, em definitivo, o regime de sesmarias.

Importantes acontecimentos históricos, como a Proclamação da República (1889) e a Constituição de 1891, não foram capazes de promover mudanças na Lei das Terras. Só em 1930 que acontece um acréscimo à Lei, autorizando a desapropriação de terra com interesse público, sendo concedida indenização ao detentor dos direitos da propriedade.

As mudanças de governos que se sucederam não implementaram mudanças significativas na questão agrária. Seja no Estado Novo de Getúlio Vargas (1937 - 1945) ou no governo do General Eurico Gaspar Dutra (1946) o que se viu foi a preservação da estrutura da propriedade da terra, ou seja, não se tocou nos latifúndios. Não houve mudanças mesmo na quinta Constituição brasileira, promulgada em 1946, que ironicamente atribuía uma nova função a terra: cumprir sua função social. Nada foi feito para que se cumprisse a tal função social. Inclusive, no Plano SALTE (Saúde, Alimentação, Transporte e Energia) não estavam previstas ações voltadas para a questão agrária. 
De igual modo, o retorno de Vargas à Presidência da República (1951), agora legitimado pelo poder popular, também não trouxe avanços na questão agrária. O que se viu foi uma grande pressão, sobretudo dos militares, para que Vargas renunciasse. A renúncia veio em 24 de agosto de 1954, por meio do seu suicídio. O curto e conturbado governo de Café Filho (1954 - 1955) menos ainda fez pela distribuição de terras.

Vitoriosos, Juscelino Kubitschek e João Goulart tomaram posse em janeiro de 1956, e implementaram um Plano de Metas que expandiu a indústria baseada nos bens de capital, aumentou a produção e a dependência externa. No campo agrário os avanços não foram significativos a ponto de mudar a estrutura fundiária.

Após sete meses do início do governo Jânio-Jango, crises e tentativas de reorganização da sociedade se sucederam. Com o acirramento das contradições as elites preparam o caminho para o golpe militar. Inicialmente aproveitaram que Jango estava fora do país e aprovaram no Congresso um ato instituindo o sistema parlamentarista. Dessa forma, Goulart assumiu a presidência com poderes reduzidos.

Se valendo do forte apoio popular, João Goulart, convocou em janeiro de 1963 um plebiscito sobre o parlamentarismo. Como saiu vitorioso, teve reestabelecido seus poderes de Presidente da República, deu início a preparação do Programa de Reforma de Base. Dentre as ações estavam previstas: reforma agrária, visando a divisão dos latifúndios. Isso desagradou setores da sociedade que não cogitavam perder seus privilégios.

As pressões vinham de todos os lados e, considerando que não poderia retroceder, Jango se vale novamente do apoio popular, convoca um comício em 13 de março de 1964 na Central do Brasil e, diante de 300 mil trabalhadores decreta a nacionalização das refinarias particulares de petróleo e a desapropriação de terras às margens das ferrovias, rodovias e zonas de irrigação dos açudes públicos.

A reação foi imediata. Setores das Forças Armadas e setores conservadores, incluindo ruralistas, organizaram a chamada Marcha da Família para Deus e pela Liberdade, com cerca de 400 mil pessoas. Poucos dias depois, mais precisamente em 31 de março, iniciou-se o movimento político-militar que veio a depor João Goulart em 01 e abril de 1964. Com o Golpe Militar, no dia 02 de abril do mesmo ano, Jango se exila no Uruguai.

Com essa rápida retomada histórica é possível perceber que, foi justamente quando um governo tomou atitude para mudar a estrutura fundiária do país as reações foram tão 
acintosas. Não é de se estranhar que, só a partir desse momento a Lei das Terras, responsável por regulamentar as relações fundiárias no país por mais de um século, foi alterada. Só em 1964, quando os militares tomaram o governo, foi elaborada e sancionada a Lei $n^{\circ}$ 4.504, instituindo o "Estatuto da Terra". Uma Lei não menos polêmica que a anterior e que, para espanto, ainda se encontra em vigor. $\mathrm{O}$ artigo primeiro da referida Lei estabelece a Reforma Agrária como: “o conjunto de medidas que visam a promover melhor distribuição da terra, modificando o regime de sua posse e uso, a fim de atender aos princípios de justiça social e ao aumento da produtividade" (BRASIL, 1964).

Importante ainda evidenciarmos que, de acordo com Delgado (2005), os debates que envolvem a questões agrárias e a Reforma Agrária, “ocorre sob circunstâncias históricas e políticas muito distintas" (DELGADO, 2005, p. 52). Ou seja, cada período histórico apresenta implicações diferenciadoras acerca das concepções, discursos teóricos e políticos a favor ou contra a Reforma Agrária, bem como das questões agrárias.

Guilherme Delgado (2005) diz ainda que, mesmo com essas diferenças, existe uma linha de continuidade nesses pensamentos, "seja a reprodução da estrutura altamente desigual de posse e uso da terra ao longo de todo o ciclo industrial (1930-1981) e também no período subseqüente de relativa estagnação (1982 - 2003)" (DELGADO, 2005, p. 52).

Percebe-se que muda o regime de posse, contudo, o aumento da produtividade, mesmo se mantendo enquanto objetivo, não se configura mais como exigência para permanência na terra. Portanto, de 1964 até hoje tivemos várias mudanças de governos, mas, muitas perguntas ainda estão sem respostas: quem tem a precisão e a capacidade de cultivar as terras devolutas do Brasil? Quem são os donos dessas terras improdutivas? Qual é a verdadeira função social da terra? Quem fiscaliza e pune os que não desempenham, integralmente, a função social da terra?

Essas questões seguem abertas, mas, é importante demarcarmos que a função social é bem definida no Estatuto da Terra, contudo, são poucas ou nenhumas as ações preconizadas pelo Estatuto e que de fato buscam: a) favorecer o bem-estar dos proprietários e dos trabalhadores que nela labutam, assim como de suas famílias; b) manter níveis satisfatórios de produtividade; c) assegurar a conservação dos recursos naturais; d) observar as disposições legais que regulam as justas relações de trabalho entre os que possuem a terra e os que a cultivam. 
Ao contrário, mesmo com a criação do Instituto Nacional de Colonização e Reforma Agrária (INCRA), em 1970, destinado a executar as ações de desapropriação e outras tarefas relacionadas à questão agrária, o que se percebe é que as ações do INCRA, hoje mais que nunca, sofreram pressões dos grandes proprietários de terra. Por conseguinte, a relação conflituosa desses proprietários com os trabalhadores do campo tem uma gênese secular que até hoje perdura e dificulta a distribuição e terras a quem de fato necessita.

Várias dessas questões também estão presentes no Assentamento Rose. Pela luta e resistência, hoje diversas famílias têm suas terras para cultivar e seu espaço de moradia. Contudo, a falta de políticas públicas voltadas para os povos do campo é grande responsável pelas dificuldades encontradas pelos campesinos.

\subsection{A constituição dos movimentos sociais campo e a luta pela reforma agrária}

Os conflitos entre proprietários e camponeses são importantes para demarcarmos os objetivos e a problematização da nossa investigação, pois essas lutas marcaram a gêneses dos movimentos sociais do campo. Já no período republicano, as chamadas lutas messiânicas, como a guerra de Canudos (1896-1897), demonstravam o poder de resistência do homem do campo. No mesmo período, o Movimento dos Contestados (1912-1916), na divisa do Paraná com Santa Catarina também influenciou outras lutas pela terra. Essas lutas regionalizadas também influenciaram o surgimento de movimentos camponeses em vários Estados, por exemplo, União dos Lavradores e Trabalhadores Agrícolas do Brasil (ULTABs), nas regiões Sul e Sudeste do país; Movimento de Agricultores Sem Terras (MASTER), no Rio Grande do Sul; e as Ligas Camponesas na região nordeste.

A maioria dessas entidades se organizavam em Estados específicos da federação. Mas, com a Comissão Pastoral da Terra (CPT), em 1975, ligada à Igreja Católica, houve um impulso para organizações com inserção nacional. A CPT conseguiu chegar a localidades onde os movimentos não alcançavam ou não eram bem recebidos.

Mesmo com contradições, disputas e divisões, inicia-se então a criação de uma rede que envolve Sindicatos de Trabalhadores Rurais, Associações voltadas para produção no campo, a Comissão Pastoral da Terra, dentre outros. 
Para Tedesco (2011), as redefinições das diretrizes de algumas ações pastorais, o surgimento da CNBB e a divulgação de algumas encíclicas papais permitiram que movimentos da Igreja Católica se aproximassem dos agricultores. Essa aproximação teve sua importância para "a consolidação do sindicalismo rural sob a égide da Igreja Católica num cenário de grandes embates políticos, ideológicos, de transformação da sociedade brasileira e dos processos produtivos no meio rural do país" (TEDESCO, 2011, p. 149).

Para o autor, as contradições estavam postas, mesmo porque existia uma apreensão de membros da Igreja Católica com o rumo político da inserção no meio rural, pois, ao aproximar-se dos movimentos camponeses poderia abrir espaços para grupos que estavam desenvolvendo ações voltadas às demandas dos camponeses, consequentemente, poderia sofrer influência ideológica. Tedesco (2011), ancorando-se nos estudos de Paulo Bassani (2009), reforça essa tese da apreensão quando diz que grupos considerados pastorais sociais, como a Ação Popular (AP) e a Ação Católica (AC), desenvolviam "ações políticas ligadas à educação rural e popular, à promoção do homem do campo, escolas rurais para alfabetizar o agricultor, assessoria no encaminhamento às documentações do agricultor junto aos sindicatos" (TEDESCO, 2011, p.151).

No entanto, essa constatação não se configura como uma crítica, mas sim uma forma de reconhecer que, mesmo diante disputas e divisões, as ações de grupos como esses citados marcaram um amplo movimento renovador do campo eclesial. Sobre essa renovação, Tedesco diz que: "visões progressistas, em adequação com a dinâmica política e social do país, no interior do comando e da oficialidade da Igreja Católica, permitiram que isso se concretizasse" (TEDESCO, 2011, p.151).

Como os conflitos por terra se acirraram no final da década de 70, o terreno ficou fértil para que uma organização com força nacional surgisse. Foi então que, em 1984, em Cascavel-PR, foi fundado o Movimento dos Trabalhadores Rurais Sem Terra (MST).

Em 1985 é criado o Ministério da Reforma e do Desenvolvimento Agrário e se reedita o Plano Nacional de Reforma Agrária. Contudo, as desapropriações e o assentamento de milhões de trabalhadores não aconteceram. Como sempre, um dos impeditivos foram as investidas dos grandes proprietários de terras. Vários conflitos se instauraram nesse período e, em contraposição, novos grupos em favor da Reforma Agrária se fortaleceram.

Essa retomada histórica da questão agrária, nos faz perceber que a aristocracia rural 


\section{Revista do Programa de Pós-Graduação em Educação da Unochapecó ISSN 1984-1566 (on-line) ISSN 1415-8175 (impressa)}

manteve e ampliou seus latifúndios sem nunca deixar de explorar a mão de obra. O que realmente surgiu como novo foi a organização dos movimentos sociais do campo, pois, como diz Carmela Panini (1990), "as contradições das forças de produção e das relações de produção, e os sucessivos confrontos é o que caracterizam o sistema agrário brasileiro. Alterações em favor dos camponeses tem decorrido, sempre, da iniciativa e das persistentes reivindicações dos mesmos" (PANINI, 1990, p. 15).

A história demonstra que os objetivos dos mecanismos legais não têm logrado êxito. Especificamente, dispositivos sobre a Reforma Agrária, Leis, Normas, Estatutos não faltam, o que falta é o cumprimento dos mesmos. A história também deixa claro que sempre houve a necessidade de uma distribuição mais justa das terras brasileiras.

A Reforma Agrária é, antes de tudo, uma ação humana e, não só uma ação revolucionária. Ideológico é o discurso que considera desnecessária qualquer mudança ou reforma profunda na estrutura agrária do país. Desse modo, para enfrentar o grave problema da questão agraria é preciso negar os discursos que defendem que o desenvolvimento agrário ocorrerá de forma gradual e sem reformas estruturantes. Que defendem que o acréscimo de fertilizantes, defensivos agrícolas e mecanização levaria a um milagroso progresso na agricultura.

Sem mudanças na estrutura agrária não se alcançará avanços no plano social. Injetar mais capital, apenas aumentando os meios mecânicos de trabalho, as máquinas ou os instrumentos de produção não é a única solução. A mudança precisa passar também pela distribuição da terra. Os dados estatísticos da agricultura brasileira demonstram que a concentração de terra-capital nas mãos de poucos continua gerando grandes distorções e conflitos. Milhões de trabalhadores brasileiros, sejam agregados, meeiros, colonos e mesmo assalariados vivem à margem de quaisquer garantias legais ou constitucionais. $\mathrm{O}$ mesmo se aplica aos assentados do Rose.

As desigualdades extrapolam as relações de produção agrícolas e alcançam as diversas ações voltadas para os campesinos. As políticas educacionais e sociais voltadas para esses povos, às disputas de terra, à criminalização dos movimentos sociais, tudo se converge numa problemática que tem como pano de fundo a questão agrária. O que vemos é que a forma de produzir e gerir do sistema capitalista não permite alterar o modelo agrário exportador e muito menos alterar a estrutura da propriedade da terra. $\mathrm{O}$ 


\section{Revista do Programa de Pós-Graduação em Educação da Unochapecó ISSN 1984-1566 (on-line) ISSN 1415-8175 (impressa)}

modelo econômico que temos cumpre o papel de manter o desenvolvimento de um Estado a serviço do capital, em detrimento da garantia dos direitos sociais para os povos excluídos.

Nessa lógica, existe uma clara oposição entre o paradigma do capitalismo agrário e o paradigma da questão agrária. O primeiro refere-se às questões agrícolas, essas, por sua vez, relacionadas aos aspectos da produção e as diferentes etapas do processo produtivo, por exemplo, quantidade produzida, preço dos produtos, consumidor, mercado etc. Buscando estabelecer as relações e dissensões entre o paradigma do capitalismo agrário e o paradigma da questão agrária, Freitas e Germani (2010) dizem que, quando o Estado assume o papel estratégico de financiar a tecnificação do território camponês com o objetivo de realizar a fluidez do capital, estamos diante do modelo de desenvolvimento justificado pelo Paradigma do Capitalismo Agrário. Esse paradigma, que se contrapõe ao Paradigma da Questão Agrária, nega a existência dos conflitos por terra como processos inerentes à contradição estrutural do capitalismo. São os defensores desse paradigma que, por dentro da estrutura governamental e legislativa, também defendem uma reforma agrária reduzida e ineficaz. Sobre essa ineficácia, lideranças do MST tercem importantes críticas acerca dos conceitos de Reforma Agrária que, por conseguinte, oferecem importantes aspectos para compreensão da política agrária brasileira.

Para Stédile (2005), a reforma agrária clássica, realizada pela burguesia industrial é uma reforma agrária capitalista que teve como objetivo: “democratizar a propriedade da terra, distribuindo a terra para os camponeses e os transformando em pequenos produtores autônomos" (STÉDILE; FERNANDES, 2005, p. 158). Ainda segundo o autor, nos países em que esse tipo de reforma foi implementada (França, EUA, Japão), o processo de desenvolvimento industrial foi acelerado à custa dos camponeses, pois esses potencializaram o mercado interno produtor de mercadorias, ganharam poder de compra e, com renda monetária, passaram a comprar bens de origem industrial.

Ao analisar o tipo de política agrícola do Estado brasileiro, Stédile (2005, p. 58) afirma que, mesmo sendo a reforma agrária clássica estritamente capitalista, a elite brasileira nunca fez a opção pela mesma, pois, sendo o Brasil refém de um capitalismo dependente, colonial, exportador, a divisão de terra para gerar crescimento econômico jamais esteve nos planos. Entende-se, portanto, que o cerne da reforma agrária é a distribuição da propriedade da terra, ou seja, a democratização da estrutura fundiária. 


\section{Revista do Programa de Pós-Graduação em Educação da Unochapecó ISSN 1984-1566 (on-line) ISSN 1415-8175 (impressa)}

Entendemos que, não alterando essa distribuição e essa estrutura, não se faz reforma agrária, mas sim, como vem fazendo o governo brasileiro, o que se realiza é uma política de assentamentos. Fazendo uma crítica a esse formato, Stédile e Fernandes (2005, p. 159) afirma: “fazer assentamentos de famílias sem-terra não significa fazer reforma agrária”. Assim defende que: "o que existe no Brasil é uma política de assentamentos sociais, em que os governos, pressionados pelos movimentos sociais, e para evitar os conflitos, resolvem conseguir algumas áreas, seja de terras públicas, seja negociadas, seja desapropriadas, e assentar famílias." (STÉDILE e FERNANDES, 2005, p.159)

Importante evidenciar que a primeira edição da obra acima foi escrita em 1999, portanto, no período do governo de Fernando Henrique Cardoso. Contudo, nos governos que o sucederam, a política agrícola brasileira não alterou seu rumo. Alguns autores (CARVALHO FILHO, 2006; OLIVEIRA, 2007; FREITAS e GERMANI, 2010, STÉDILE, 2015) não titubeiam ao defender que também nos mandatos posteriores, dados do Plano Nacional de Reforma Agrária (PNRA) foram mascarados e não se avançou com um projeto para superar a desigualdade e a exclusão social dos povos do campo. O MST (2015), em artigo publicado em sua página apresenta os seguintes dados: "O Brasil se mantém como um dos países do mundo com maior concentração de terras. Cerca de 200 mil camponeses continuam sem ter uma área para cultivar, um problema que o primeiro governo da presidente Dilma Rousseff fez muito pouco para aliviar”. Seguem dizendo que: “A CPT realizou um balanço dos fatos ocorridos no quadriênio 2011-2014, que apresenta os piores indicadores em matéria de Reforma Agrária dos últimos 20 anos” (MST, 2015).

Diante da política agrária existente no Brasil, muito ainda se tem a lutar para que os princípios básicos dos direitos humanos sejam respeitados. O MST assume novamente o protagonismo na luta pela reforma agrária, lançando em 2014 uma pauta que apresenta a Reforma Agrária Popular. Na prática, a proposta vem defender que a luta pela terra não pode ser exclusivamente uma preocupação de camponeses e pequenos agricultores, precisa sim ser uma luta de toda a sociedade brasileira. Como diz Bicalho (2021, p. 11), essa é uma luta dos sujeitos, individuais e coletivos, por direitos sociais.

A Reforma Agrária Popular associa a luta pela terra com a luta pela superação da pobreza e das desigualdades sociais. É nesse contexto que a luta deve apresentar alternativas ao modelo agrícola vigente. Desse modo, para o Movimento, é preciso inverter 
as prioridades: em vez do agronegócio, a agroecologia. Que se defenda o meio ambiente e os trabalhadores rurais. Que se efetive a democratização da terra, priorizando a produção de alimentos saudáveis - através da agroecologia - e que se garanta direitos básicos, como saúde, educação, acesso a tecnologias, cultura e lazer a toda a população do campo.

Se a questão agrária apresenta tantas mazelas, para romper o silêncio, contribuir para afirmação da identidade campesina é preciso se dispor a lutar com os camponeses e não apenas lutar por eles. É preciso oportunizar que as vozes dos povos do campo ecoem em todos os espaços sociais, inclusive no âmbito acadêmico. Por estarmos aliados com como a afirmação camponesa é que nos propomos conhecer e difundir os saberes e as formas de organização política, social e produtiva do Assentamento Rose.

\section{CONSIDERAÇÕES FINAIS}

Chega, enfim, o momento do "descomeço ${ }^{10}$ " do verbo. Como alguns preferem, o momento das considerações finais. Como as cores das pessoas e do Assentamento Rose ampliaram nossos olhares, não caberia um fim, mas também um “descomeço". Cabe a nós seguirmos ouvindo, pois já não vamos mais sozinhos. É nessa travessia, em que outros caminham conosco, que os movimentos polifônicos e polissêmicos possibilitam uma unidade de pensamento. A voz que agora apresentamos trazem nossas subjetividades, essas construídas juntamente com as vozes dos assentados do Rose.

Conforme dito anteriormente sobre os vôos alçados, os diálogos (in) comuns que possibilitam a emersão de saberes e oxigenam o processo de emancipação no Assentamento Rose perpassa todas as gerações, vão das crianças vereadoras e prefeitas aos griôs sissaleiros. Muitos que foram crianças no Rose transformaram seus sonhos em realidade. Hoje são pessoas formadas nas diversas áreas ligadas às ciências da terra; vários (as) professores (as), poetisas e escritoras e diversos profissionais de outras áreas: tem enfermeira, tem advogado, tem filosofo, tem gente emancipada e competente. Pessoas essas que um dia foram estigmatizados como sem-terra. Sobretudo, no Rose tem gente

\footnotetext{
${ }^{10}$ Expressão utilizada por Manoel de Barros no poema Uma Didática da Invenção. In: BARROS, Manoel de. O livro das ignorãças. Rio de Janeiro : Alfaguara, 2016.
} 
que acredita em gente. Tem gente que acredita na força da terra.

O que vivemos no Assentamento Rose em nada nos remete às relações verticalizadas entre investigadores e investigados. Tudo que partilhamos com as lideranças e as crianças juntamos em nossas mãos, agasalhamos nas nossas memórias e juntamos tudo num "potinho" chamado identidade. Assim, não caminhamos mais da mesma forma. Como nos ensina Manoel de Barros, fomos com enxadas às costas e nos tornamos caçadores de achadouros de infâncias e de vidas. Caminhar pelas manhãs e noites camponesas do Rose, nos deu a certeza de que não há espaço para medos e nem se faz necessário arremedos para enganar a necessária luta pela terra, pois, a verdade será cantada simples e sempre; afinal, o que vale é a alegria que se constrói dia a dia. O que vale é partilhar saberes e contribuir para um mundo mais humano.

\section{REFERÊNCIAS}

BASSANI, P. Frente Agrária Gaúcha e Sindicalismo de Trabalhadores Rurais. Canoas/Londrina: ULBRA/EDUEL, 2009.

BOGO, Adermar. Identidade e luta de classes. -- 2.ed.- São Paulo: Expressão Popular, 2010.

BRASIL, Lei $N^{\circ} 4.504$, de 30 de novembro de 1964. Dispõe sobre o Estatuto da Terra, e dá outras providências. Presidência da República, Casa Civil. Brasília, 1964.

DELGADO, G. A questão agrária no Brasil, 1950-2003. In.: JACCOUD, L. (org.). Questão social e políticas sociais no Brasil contemporâneo. 1a.ed. Brasília: IPEA, 2005.p. 51-90

FREITAS, Hingryd Inácio de. GERMANI, Guiomar Inez. A Questão da Reforma Agrária e a Política de Desenvolvimento Territorial Rural no Litoral Sul da Bahia. In.: XVI Encontro Nacional dos Geógrafos: crises, práxis e autonomia. Porto Alegre/RS, 2010.

GUIMARÃES, Alberto Passos. Quatro Séculos de Latifúndio. $4^{\text {a }}$ edição Rio de Janeiro, Editora Paz e Terra, 1997. In. STEDILE, João Pedro (org). A questão agrária no Brasil: O debate tradicional -1500-1960. 2. ed. - São Paulo: Expressão Popular, 2011.

MST, Movimentos dos Trabalhadores Rurais Sem Terra. Cerca de 200 mil camponeses continuam sem ter uma área para cultivar. Disponível em:

http://www.mst.org.br/2015/02/28/cerca-de-200-mil-camponeses-continuam-sem-ter-umaarea-para-cultivar.html, 2015. Acesso em: 09/07/2018.

NASCIMENTO, Edisvânio P. Narrativas Sisaleiras: dizeres, saberes orais, fazeres e 
projetos culturais no Assentamento Rose. 2018. Mestrado - Universidade do Estado da Bahia. Programa de Pós-Graduação em Crítica Cultural. Campus II. Alagoinhas, BA, 2018.

OLIVEIRA, Ariovaldo Umbelino. Modo de Produção Capitalista, Agricultura e Reforma Agrária. São Paulo: Labur Edições, 2007.

PANINI, Carmela. Reforma Agrária dentro e fora da lei: 500 anos de história inacabada. São Paulo: Paulinas, 1990.

PELOSO, Ranulfo. Trabalho de Base: seleção de roteiros organizados pelos Cepis. São Paulo: Expressão Popular, 2012.

POLLAK, Michael. Memória e Identidade Social. (Conferência). Estudos Históricos, Rio de Janeiro. Vol. 5, nº 10, 1992, p. 200-212

SANTOS, R. B. A dimensão educativa e o fazer pedagógico no Movimento dos Trabalhadores Rurais Sem Terra. Revista Pedagógica, v. 23, p. 1-21, 2021. DOI http://dx.doi.org/10.22196/rp.v22io.5574

STEDILE, João Pedro. FERNANDES, Bernardo Mançano. Brava Gente: a trajetória do MST e a luta pela terra no Brasil -- 3. ed. -- São Paulo/SP. Editora Fundação Perseu Abramo, 2005.

STEDILE, João Pedro. A questão agrária no Brasil: O debate tradicional - 1500-1960.2. ed. - São Paulo: Expressão Popular, 2011.

STEDILE, João Pedro. Entrevista na TV Brasil, no Programa O Espaço Público. 10/03/2015.

TEDESCO, João Carlos. Conflitos de interesses e tutela camponesa: o associativismo católico no RS - décadas de 1950 e 1960. Diálogos, v. 15, n. 1, p. 147-176, 2011. DOI: 10.4025/dialogos.v15i1.473.

VINHAS, M. Problemas Agrário-Camponeses do Brasil. Rio de Janeiro. Editora Civilização Brasileira, 2011. In. STEDILE, João Pedro (org). A questão agrária no Brasil: O debate tradicional - 1500-1960.2. ed. - São Paulo: Expressão Popular, 2011.

\section{REFERÊNCIAS DAS NARRATIVAS}

LEVINHO. Entrevista concedida aos investigadores. Assentamento Rose, Santaluz, BA, 2019.

LOLÔ. Entrevista concedida a NASCIMENTO, Edisvânio Pereira. Assentamento Rose, Santaluz, BA, 2018.

ROQUINHO. Entrevista concedida a NASCIMENTO, Edisvânio Pereira Assentamento Rose, 


\section{REVISTA}

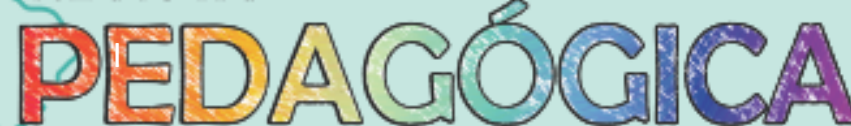

Revista do Programa de Pós-Graduação em Educação da Unochapecó

ISSN 1984-1566 (on-line) ISSN 1415-8175 (impressa)

Santaluz, BA, 2018.

SASSÁ. Entrevista concedida aos investigadores. Assentamento Rose, de Santaluz, BA, 2019.

SOL. Entrevista concedida aos investigadores. Assentamento Rose, Santaluz, BA, 2019.

ZICKS MUSICAL. Entrevista concedida aos investigadores. Assentamento Rose, Santaluz, BA, 2019.

Recebido em: 29-06-2021

Aceito em: 26-08-2021

Publicado em: 12-10-2021 